\title{
Thermoelectric Generator for the Recovery of Energy from the Low-Grade Heat Sources in Sugar Industry
}

\author{
Weera Punin, Somchai Maneewan, Chantana Punlek \\ Research and Energy Management Center, Department of Physics, Faculty of Science, Naresuan University, Thailand
}

\begin{tabular}{l}
\hline \hline Article Info \\
\hline Article history: \\
Received Mar 1, 2018 \\
Revised Aug 23, 2018 \\
Accepted Sep 14, 2018 \\
\hline
\end{tabular}

\section{Keyword:}

Thermoelectric modules

Waste heat recovery

Power generation

Sugar industry

Seebeck effect

\begin{abstract}
In the current work, a thermoelectric power generation system was designed for an assessment of opportunities in terms of electricity production through the utilization of waste heat from sugarcane industries. In this study, the thermoelectric cooling of TEC1-12708T200 was appropriate for use in electric power generation from low-grade heat sources. The experiments used ten thermoelectric modules and an aluminum water block installed on the exterior surface area of a sugar boiler to achieve the same water flow as a traditional system. The results revealed that the power generation system could generate about $30 \mathrm{~W}(25.7 \mathrm{~V}, 1.17 \mathrm{~A})$ at a matched load of approximately $36.8 \Omega$. The thermoelectric power generation system could convert $12.5 \%$ of heat energy into electrical energy. Therefore, the thermoelectric power generation system designed in this study could be an effective alternative for waste heat recovery in sugarcane industries.
\end{abstract}

Copyright $(2018$ Institute of Advanced Engineering and Science. All rights reserved.

\section{Corresponding Author:}

Somchai Maneewan,

Research and Energy Management Center,

Department of Physics, Faculty of Science, Naresuan University

99 Moo 9, Tambon Tha Pho, Mueang Phitsanulok, Phitsanulok 65000, Thailand.

Email: somchaim@nu.ac.th

\section{INTRODUCTION}

Thailand is one of the main producers and exporters of sugar as well as sugar products. There are currently 53 sugar mills distributed throughout Thailand, with the growth of sugarcane production expected to reach more than $115 \mathrm{Mt}$ of cane in 2020 . The Thai sugarcane industry is also the largest energy-consuming sector in the country as evidenced by a $36 \%$ share of total final energy consumption in 2015. [1]. The energy used in sugar mills is supplied by bagasse, which can be estimated from the amount of bagasse utilized and its heating value [2]. Essentially, $100 \mathrm{~kg}$ of crushed sugarcane produces approximately $29 \mathrm{~kg}$ of bagasse and the net calorific value of bagasse at $50.7 \%$ moisture is $7.37 \mathrm{MJkg}^{-1}$ of bagasse [3]. Bagasse energy is used in sugar production processes at approximately $73-79 \%$ efficiency and the remaining $16-20 \%$ is lost, whereas about $12 \%$ is lost in form of waste heat from the external boiler [4]. As a result, the average temperature of the external surface area of the boiler is about $200{ }^{\circ} \mathrm{C}$ [5],[6]. If this portion of waste heat could be converted into electrical energy and utilized by the boiler, the efficiency of the boiler could be improved significantly. Thermoelectric (TE) conversion represents a promising technology that can make use of this waste heat. A thermoelectric generator (TEG) is a solid-state device that can convert heat directly into electrical energy when subjected to an appropriate temperature difference [7],[8]. The main advantages of TEG include direct conversion from thermal to electrical energy, high reliability, minimal maintenance requirements, and a lack of moving parts that can cause noise and vibration. In addition, it does not produce pollution [9].

TEG modules can be exploited to harvest waste heat from industrial operations such as biomass boilers [10], small-scale pellet boilers [11], cement plants [12] and other heating components like wood burning stoves [13], biomass gasifiers [14], and among others such as improving the performance of a photovoltaic cell [15], an electrical power generator by using TEG, focal lens and underground heat 
dissipation system [16], and hybrid thermoelectric generator [17],[18]. Many researchers have explored this technology. Zhou et al. [19] investigated various transport phenomena and suggested design optimization for an exhaust-based TEG system in an internal combustion engine. A multi-element TEG was investigated with the irreversibility of finite-rate heat transfer. Performance is analyzed on the basis of heat transfer influence and the number of elements. Conclusively, the optimal current and optimal number of thermocouples must be selected in order to obtain the best performance. Chandy et al. [20] designed an automobile exhaust TE heat exchanger system for waste heat recovery from an automobile engine using ANSYS. The cold side heat exchanger analysis was done at $-6{ }^{\circ} \mathrm{C}$ and the hot side heat exchanger was analyzed at $327{ }^{\circ} \mathrm{C}, 477^{\circ} \mathrm{C}, 627^{\circ} \mathrm{C}$, and $927^{\circ} \mathrm{C}$. The results of the study showed that the voltage, current, power developed and overall efficiency of the system increased with an increase in engine speed.

Previously, Hsiao-Kang et al. [21] investigated the use of waste heat recovered from a biomass gasifier. The results showed that the maximum power output of the TEG system was $6.1 \mathrm{~W}$, while TEG power density was approximately $193.1 \mathrm{Wm}^{-2}$. Barma et al. [22] estimated the amount of electrical power produced by the TEG placed between a flue gas duct and fresh air duct of an industrial thermal oil heater. TE materials could be enhanced by up to $8.18 \%$. The specifications of plate fin heat sinks as well as TE properties of the p-n materials of the system have a substantial impact on the performance of a TEG module. Baskar et al. [23] carried out an experiment to study and analyze the feasibility of retrofitting a waste heat recovery system to a two-stroke petrol engine. Experimental performance testing showed that the overall efficiency of the two-stroke petrol engine, with and without the waste heat recovery system, was $29.67 \%$ and $29.2 \%$, respectively, when the power extraction was $90 \mathrm{~W}$. Wang et al. [24] worked on two-stage optimization of a heat exchanger to improve the performance of a TEG; the TEG power output density increased by $88.70 \%$. Hsiao et al. [25] constructed a mathematical model to predict the performance of a TEG module attached to a waste heat recovery system. The results showed that the TEG module presented better performance on the exhaust pipe than on the radiator. Champier et al. [26] combined a biomass cook stove with a TEG to recover waste heat and generate electric power. The optimal placement of the TEG on the stove was also investigated. Niu et al. [27] connected 56 BiTebased TEG modules in series to show the encouraging potential of using TEG for low-temperature waste heat recovery, which also showed good conversion efficiency at about 4.44\%. Maneewan and Chindaruksa [28] investigated the characteristics and performance of TE modules for power generation at low temperatures by using waste heat from biomass drying. The results showed that the power generation system could generate about $22.4 \mathrm{~W}(14 \mathrm{~V}, 1.6 \mathrm{~A})$ with an air flow of $9.62 \mathrm{~m}^{3} \mathrm{~s}^{-1}$. The TE module could convert $4.08 \%$ of heat energy into electrical energy. Nuwayhid et al. [29] developed and tested a low-cost, high-performance TE module fitted to the upper right hand corner of a common domestic wooden stove. A maximum of $4.2 \mathrm{~W}$ was obtained from a single TEG module at a temperature difference of $88^{\circ} \mathrm{C}$.

In addition, Gou et al. [30] offered suggestions to enhance TEG performance, such as increasing the waste heat temperature, expanding the heat sink surface area in the proper range and enhancing cold-side heat transfer capacity. As the source of the TEG is low-grade waste heat, which is cheap or free, as well as the fact that there is no fresh consumption of fuel for electricity production, it will be able to obtain additional benefits in terms of improved overall efficiency. This study aimed to investigate the characteristics and performance of TE modules for power generation at low temperatures by using waste heat from the exterior surface area of a sugar boiler in the sugarcane industry. Importantly, this study generates references for the design of TE power generation systems in the future.

\section{RESEARCH METHOD}

The TE modules were considered appropriate for use in operating the waste heat from the sugarcane industry at low temperature (about $200{ }^{\circ} \mathrm{C}$ ). In order to carry out the experiment, the authors selected the TE cooling and power modules shown in Table 1 . These modules were chosen specifically based on their low cost and commercial availability. The TE module is connected to an external resistor load and the output voltage measured by a digital multimeter in parallel with the circuit. The power generated by the TE module can be calculated using the voltage and resistor values. The results will be illustrated by the experimental setup for a TE modules test; two TE cooling modules and two TE power modules were selected for testing purposes.

Int J Pow Elec \& Dri Syst, Vol. 9, No. 4, December 2018 : 1565 - 1572 
Table 1. Characteristics of various commercially available thermoelectric modules

\begin{tabular}{lcccc}
\hline & \multicolumn{2}{c}{ TE cooling modules } & \multicolumn{2}{c}{ TE power modules } \\
\multicolumn{1}{c}{ Parameters } & TEC1- & TEC1- & TEP1- & TEG1- \\
& $12708 T 200^{\mathrm{a}}$ & $12703^{\mathrm{b}}$ & $126 \mathrm{~T} 200^{\mathrm{a}}$ & $127-40-40-250^{\mathrm{a}}$ \\
\hline TE module sizes (mm) & $40 \times 40 \times 3.4$ & $40 \times 40 \times 3.8$ & $40 \times 40 \times 3.3$ & $40 \times 40 \times 3.7$ \\
Max. Operating hot-side temp. $\left({ }^{\circ} \mathrm{C}\right)$ & 200 & 200 & 200 & 250 \\
Max. output power (W) & 74 & 31.5 & 3.96 & 7.8 \\
Max. output current (A) & 8 & 3 & 0.96 & 1.5 \\
Max. output voltage (V) & 15.4 & 15.4 & 8.4 & 10.4 \\
No. of couples & 127 & 127 & 126 & 127 \\
Module cost (US\$) & 9.52 & 8.9 & 13.32 & 12 \\
\hline
\end{tabular}

Source: ${ }^{\mathrm{a}}$ Specification of TE Modules [31]; ${ }^{\mathrm{b}}$ Specification of TE Modules [32]

\subsection{Generation Performance Test of TEG modules}

The experimental setup for generation performance test of the TE modules is illustrated in Figure 1. The setup includes: (1) the electric heater; (2) the TE module; (3) the water cooling system; and (4) the data acquisition system. The TE modules are clamped between a water block (the water cooling system (water pump and radiator) uses $100 \mathrm{~W}$ of electricity) and the electric heater $(2,700 \mathrm{~W}$ at $20 \mathrm{~cm} \mathrm{x} 40 \mathrm{~cm})$. Electric heating is carried out using a plate-type heat exchanger with coolant (water) flowing through the interior channels of the water block to control the cold-end temperature of the TE module. The water flows through these channels, absorbing excess heat from the cold side of a TE module, which then exits the water block on its way to a radiator. At the radiator, the water is pushed through a network of even narrower channels, which are cooled by having air blown over them by a fan. The water then flows back to the reservoir and begins its journey again.

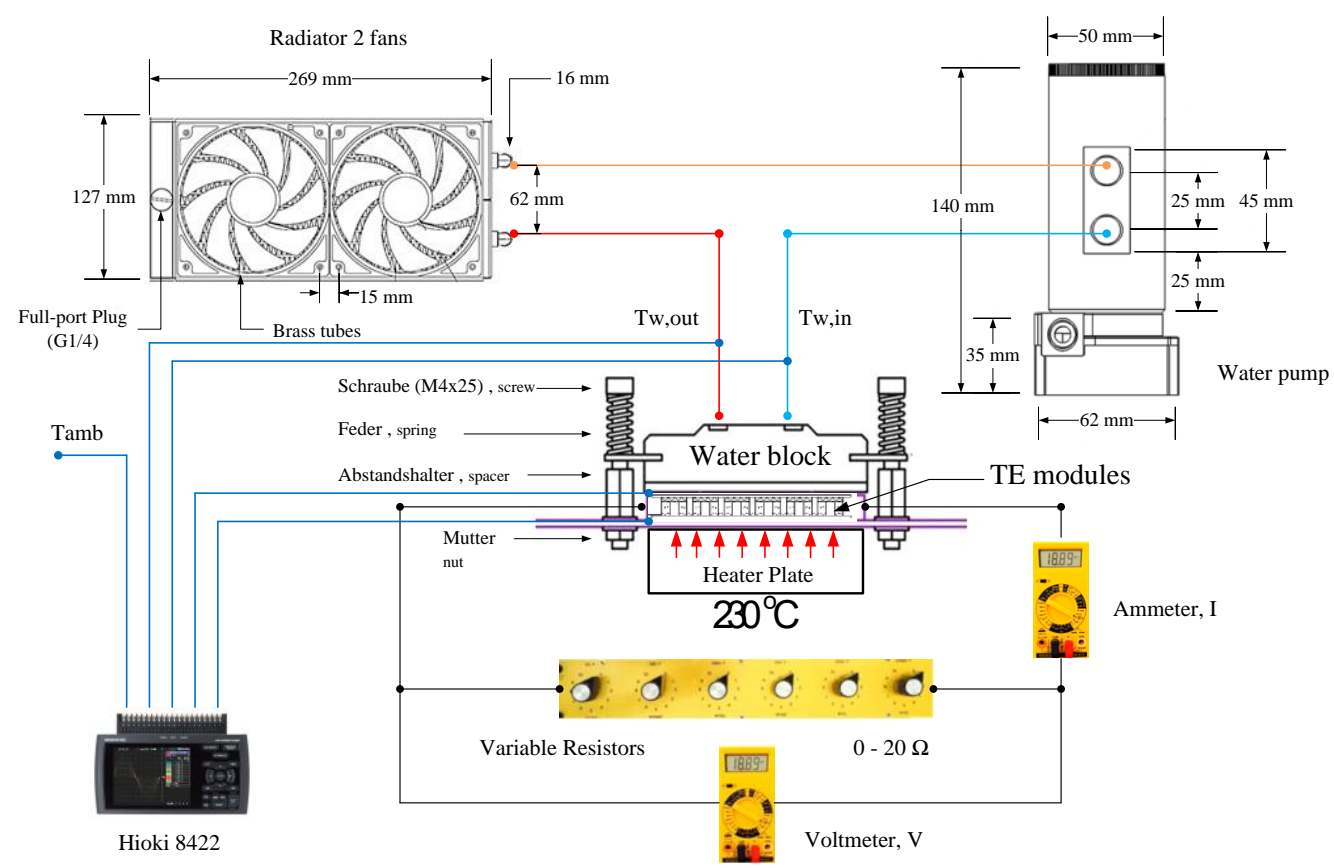

Figure 1. Diagram of the experimental setup and laboratory-scale testing facilities

Investigations were carried out by controlling the temperature differences between the hot side and cold side of the TE modules to be $100{ }^{\circ} \mathrm{C}, 150{ }^{\circ} \mathrm{C}$, and $200{ }^{\circ} \mathrm{C}$. An experimental setup was built to compare power generation as well as to measure the effect of load resistance $\left(\mathrm{I}_{\mathrm{sc}}, \mathrm{V}_{\mathrm{oc}}\right.$, and 2-20 $\Omega$ ) between the TE cooling and power modules.

\subsection{System Design and Installation}

The TE power generation system was designed for the assessment of cogeneration opportunities for sugarcane industries and the production of electricity from waste heat. The sugarcane industry normally meets its process heat energy needs by producing hot water, low pressure, low-temperature steam, medium

Thermoelectric Generator for the Recovery of Energy from the Low-Grade Heat Sources .... (Weera Punin) 
pressure and medium temperature steam, or high pressure and superheated steam. Meanwhile, electrical energy needs for drives and illumination are met by the electrical grid. From data on the combustion chamber of a sugar boiler, it was found that the average temperature at the front of the wall of the heat exchanger was about $150-250{ }^{\circ} \mathrm{C}$ (average $200{ }^{\circ} \mathrm{C}$ ). These locations for the TE power generation system were chosen for ease of installation, as shown in Table 2. In this case, therefore, the researchers used ten TE modules and an aluminum water block to achieve the same water flow as a traditional system, which were divided into two parallel systems, one of which consisted of five TE modules in series used for the assessment of electric power produced by waste heat.

Table 2. Temperatures for the exterior surface of the boiler

\begin{tabular}{cccc}
\hline $\begin{array}{c}\text { Surface area of } \\
\text { boiler }\end{array}$ & \multicolumn{3}{c}{ Temperatures of the surface area of a boiler } \\
Min. Temp. $\left({ }^{\circ} \mathrm{C}\right)$ & Max. Temp. $\left({ }^{\circ} \mathrm{C}\right)$ & Avg. Temp. $\left({ }^{\circ} \mathrm{C}\right)$ \\
\hline Area A & 151 & 249 & 200 \\
Area B & 150 & 250 & 200 \\
Area C & 147 & 248 & 198 \\
Area D & 149 & 249 & 199 \\
Area E & 150 & 250 & 200 \\
\hline
\end{tabular}

The experiment investigated power generation by a TE power generation system installed on the exterior surface area of a boiler. Figure 2 shows the layout used in this experiment. The equipment used includes (1) the TE power generation system, (2) the water cooling system, (3) a test section (heating and cooling devices), and (4) the data acquisition system. The TE modules were clamped between an aluminum water block and the exterior surface area of the boiler (waste heat source). The low-grade temperature from boiler operation was transferred through the TE conversion device in such a way that ensured maximum heat exchange. Heating came from an aluminum plate-type heat exchanger with cooling (water) flow through a thin surface layer of silicon to control the cold-end temperature of the TE module. A substantial temperature difference between the hot side and cold side of the TE module resulted in efficient conversion of thermal energy into electricity. The coolant was supplied from a cold reservoir. The temperature of the coolant was controlled using a $240 \mathrm{~mm}$ radiator.

The combustion chamber of a boile

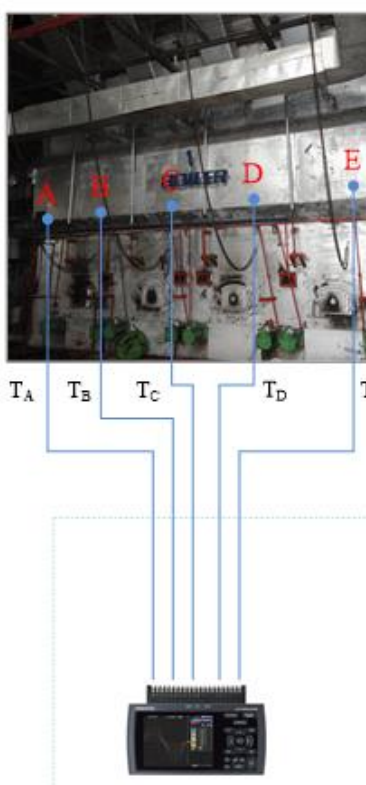

Hioki 8422

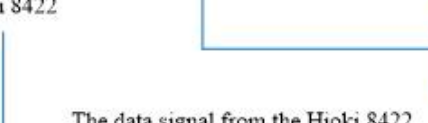

The data signal from the Hioki 8422
TE power generation system

Water block
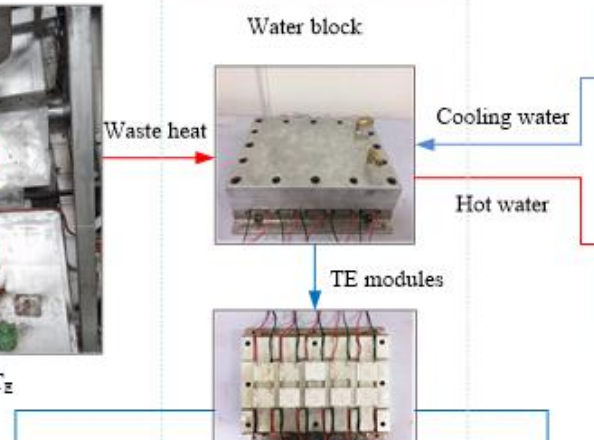

The water cooling system

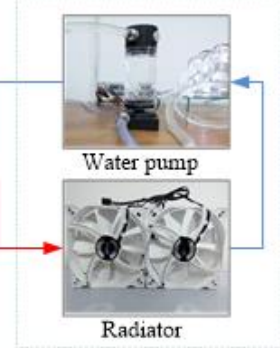

Radiator

The data acquisition system

Ammeter, I RS 232

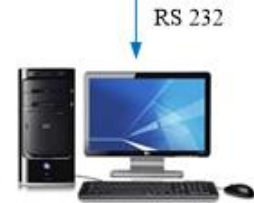

RS 232
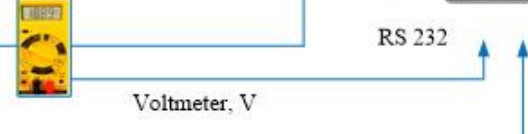

Figure 2. Schematic diagram of TE power generation using waste heat from the boiler 
The data acquisition system monitored and recorded the relevant temperatures, water flow rate, and voltage and power outputs in real time. A K-type thermocouple was embedded between the hot side surface area of TE power generator modules and an aluminum plate heat exchanger as well as the cold side surface area of TE power generation modules. Measurements of the voltage generated by the TE power generation system were monitored by data logging voltmeter in real time. The output of the thermocouple was measured through a Data Logger (Hioki 8422) and sent to a PC for real-time analysis and recording. The flow rate of water cooling delivered by the water pump was measured at the water outlet and downstream of the test section using a water flow meter.

\section{RESULTS AND ANALYSIS}

The temperature differences between the hot side and cold side were varied to study the characteristics of the TE module. The researchers found that the hot-side temperature varied between $0{ }^{\circ} \mathrm{C}$ and $250{ }^{\circ} \mathrm{C}$. In addition, there was a limit to the maximum operating temperature of the hot side of the TE cooling module and power module of about $150-250{ }^{\circ} \mathrm{C}$ (average $200{ }^{\circ} \mathrm{C}$ ) and for the cold side at a temperature of between $25-35^{\circ} \mathrm{C}$ (average $30{ }^{\circ} \mathrm{C}$ ). The laboratory experiments showed that the TE cooling and power modules could generate a maximum power output of about 13 to $15 \mathrm{~W}$ and 7 to $10 \mathrm{~W}$ per module, respectively.

\subsection{Effect of Load Resistance on Power Generation}

In this section, the researchers analyzed the relationship between external load resistors and the output voltage of the TE cooling and power modules. The results showed that when the temperature difference between the hot and cold side of the $\mathrm{TE}$ module was $\Delta \mathrm{T}=\mathrm{T}_{\mathrm{h}}-\mathrm{T}_{\mathrm{c}}$, a larger load resistor corresponded to a greater output voltage of the TE module. The output voltage of TEG module resulting from the Seebeck Effect is the product of Seebeck coefficient multiplied by the temperature difference between the hot and cold sides of the TE module. Therefore, an increase in the external load resistor may also increase the Seebeck coefficient of the TE module (Figure 3).

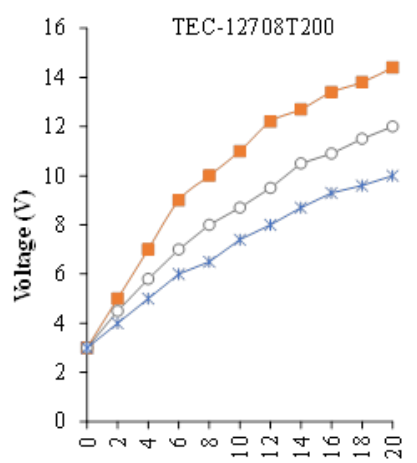

Extemal resistance $(\Omega)$

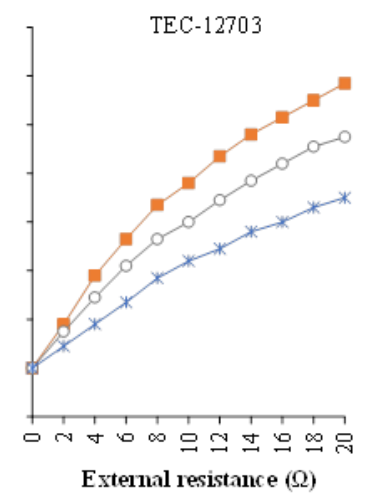

Extemal resistance $(\Omega)$
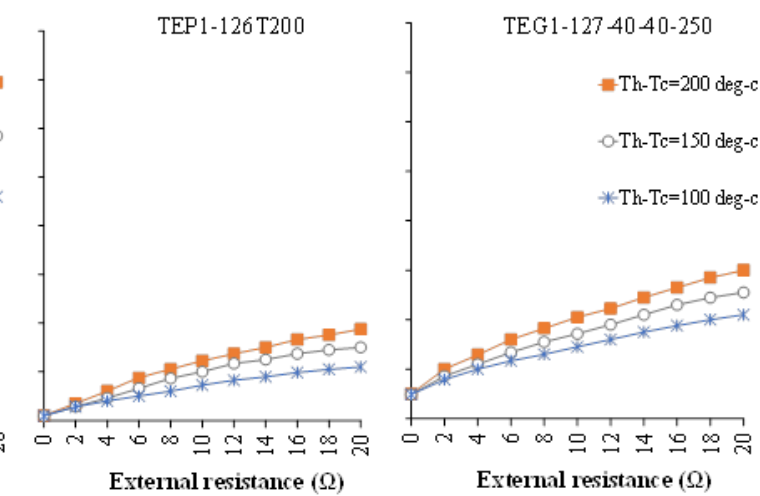

Figure 3. External resistance versus output voltage of the TE module

Figure 4 illustrates the evolution of the power output versus time for generating power by the TE module at load resistances ranging from 2 to $20 \Omega$. The rate of power generated by the TE cooling module decreased at the same rate generated by the power module, while resistance increased. Consideration of the optimum load depends on the internal resistance of the TE module. The TE cooling module of TEC112708T200 could generate a maximum power output of about $14.6 \mathrm{~W}$ per module at a matched load of about $3.8 \Omega$. Based on the maximum power transfer theory, maximum power conversion occurs when the external load resistor equals the internal resistance. 


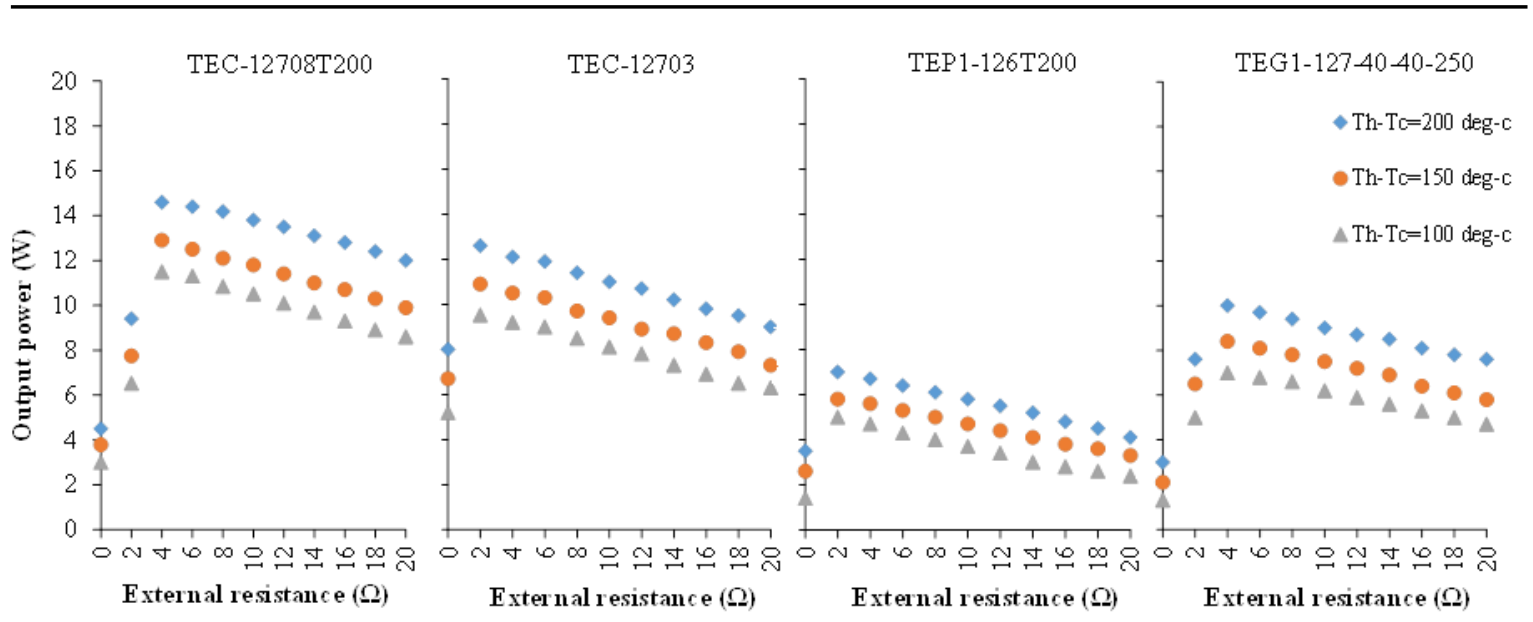

Figure 4. External resistance versus power output of the TE module

\subsection{Electrical Cost}

A comparison of electrical energy costs per module between the TE cooling modules and power modules is shown in Figure 5. From calculations in this work, it was found that electrical energy costs for TEC1-12708T200 were US\$ 0.085 per $\mathrm{kWh}$, which is comparable to that of TEC1-12703 and much lower than those of TEP1-126T200 and TEG1-127-40-40-250. Therefore, the TE cooling module is an interesting and novel alternative for power generation from waste heat. In this study, the researchers selected the TEC1$12708 \mathrm{~T} 200$ for power generation by waste heat from the exterior surface area of a boiler, especially in lowheat regain. (Remark P is power (W), EC is energy cost calculated based on TE lifetime of about 100,000 h (US\$/kWh)).

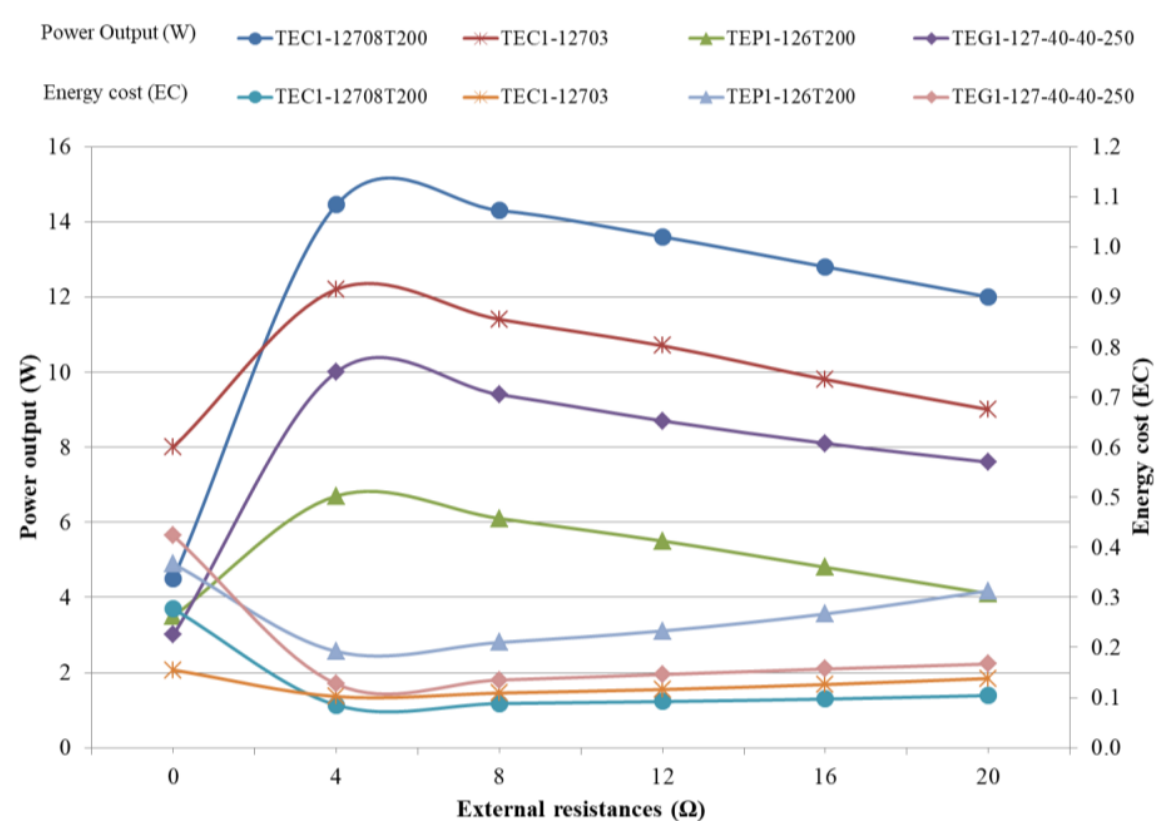

Figure 5. Comparison of electrical costs between TE cooling and power modules

\subsection{System Efficiency}

In this section, the researchers used actual sugar production in the sugarcane industry to investigate waste heat recovery, with test results coming from a specially-designed TE conversion system installed on the exterior surface area of the boiler. The variables discussed include the flow rate (LPM) of cooling water by a water pump, external load resistors, and power output. 
In Figure 6, it can be seen that the external load resistors have a significant effect on power generation, which goes up with an increase of the external load resistors. Within the current range of cooling water flow rate used in this experiment, an increase of cooling water flow rate did not increase generated power. At the load range of $0-50 \Omega$, the maximum TE cooling generation power output is achieved when the external load resistor is approximately $36.8 \Omega$. Based on the maximum power transfer theory, maximum power conversion occurs when the external load resistor is equal to the internal resistance. The internal resistance of the TE power generation system is roughly $38 \Omega$. A maximum output of $30 \mathrm{~W}$ is achieved when the temperature difference between the hot and cold sides of the TE cooling modules is $200{ }^{\circ} \mathrm{C}$, where system efficiency is $12.5 \%$.

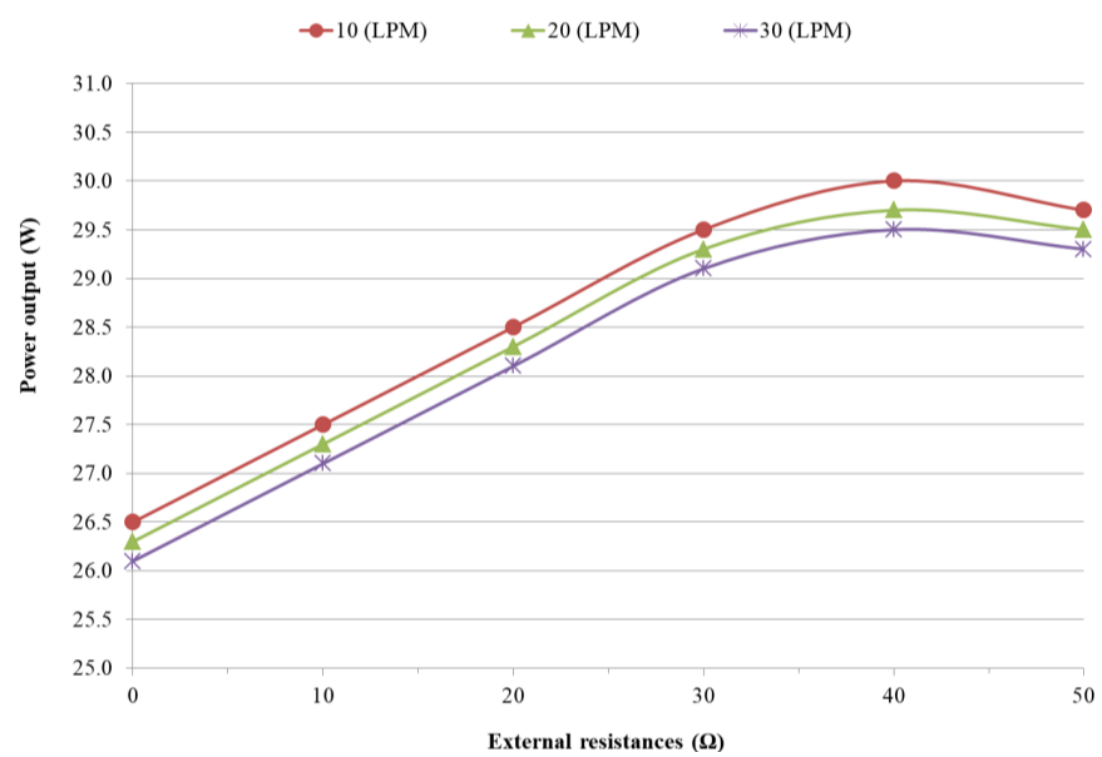

Figure 6. External resistance versus power output of the TPG system (TEC1-12708T200)

\section{CONCLUSION}

The TE power generated from the waste heat of the sugarcane industry at a wall temperature of about $200{ }^{\circ} \mathrm{C}$ has potential use, especially with the TE cooling of TEC1-12708T200. The power generated for this TE power generation system was approximately $30 \mathrm{~W}$ at a matched load of about $36.8 \Omega$. The TE power generation system is able to convert $12.5 \%$ of the heat energy into electrical energy. Therefore, the TE power generation system design is potentially useful for waste heat recovery in the sugar manufacturing industries.

\section{ACKNOWLEDGEMENTS}

This research was financially supported by the Energy Policy and Planning Office (EPPO), Ministry of Energy is gratefully acknowledged. The cooperation of the Office of The Cane and Sugar Board (OCSB), the pilot plant development and various sugar mills in providing information and assistance are deeply appreciated. Thanks are also due to the support of Research and Energy Management Center, Department of Physics, Faculty of Science, Naresuan University, Phitsanulok (Thailand).

\section{REFERENCES}

[1] Department of Alternative Energy Development and Efficiency (DEDE), "Thailand energy statistics," Available on http://www.dede.go.th/dede. Accessed 29 April 2017.

[2] F. A. Pazuch, et al., "Economic evaluation of the replacement of sugar cane bagasse by vinasse, as a source of energy in a power plant in the state of Paraná, Brazil," Renewable and Sustainable Energy Reviews, vol. 76, pp. 34 42, 2017.

[3] Office of the Cane and Sugar Board (OCSB), "Thailand sugar production report," Available on http://www.ocsb.go.th. Accessed 29 April 2017.

[4] S. Sathitbun-anan, et al., "Energy efficiency and greenhouse gas emission reduction potentials in sugar production processes in Thailand," Energy for Sustainable Development, vol. 23, pp. 266-274, 2014. 
[5] B. Patro, "Efficiency studies of combination tube boilers," Alexandria Engineering Journal, vol/issue: 55(1), pp. 193-202, 2016.

[6] Zhang J. and Wang G., "Energy saving technologies and productive efficiency in the Chinese iron and steel sector," Energy, vol/issue: 33(4), pp. 525-537, 2008.

[7] Liang X., et al., "Comparison and parameter optimization of a two stage thermoelectric generator using high temperature exhaust of internal combustion engine," Applied Energy, vol/issue: 130(1), pp. 190-199, 2014.

[8] Xiao H., et al., "A flameless catalytic combustion-based thermoelectric generator for powering electronic instruments on gas pipelines," Applied Energy, vol. 112, pp. 1161-1165, 2013.

[9] S. Yu, et al., "Start-up modes of thermoelectric generator based on vehicle exhausts waste heat recovery," Applied Energy, vol. 138, pp. 276-290, 2015.

[10] M. Brazdil and J. Pospisil, "Thermoelectric Power Generation Utilizing the Waste Heat from a Biomass Boiler," Electronic Materials, vol/issue: 42(7), pp. 2198-2202, 2013.

[11] K. Alanne, et al., "Analysis of a wooden pellet-fueled domestic thermoelectric cogeneration system," Applied Thermal Engineering, vol/issue: 36(1), pp. 1-10, 2014.

[12] Q. L. P. Li, et al., "A Thermoelectric Waste-Heat-Recovery System for Portland Cement Rotary Kilns,” Electronic Materials, vol/issue: 44(6), pp. 1750-1762, 2015.

[13] Champier D., et al., "Thermoelectric power generation from biomass cook stoves," Energy, vol/issue: 35(2), pp. 935-942, 2010.

[14] Ueki Y., et al., "Gasification characteristics of woody biomass in the packed bed reactor," Proceedings of the Combustion Institute, vol. 33, pp. 1795-1800, 2011.

[15] A. Lekbir, et al., "The Recovery of Energy from a Hybrid System to Improve the Performance of a Photovoltaic Cell," International Journal of Power Electronics and Drive System, vol/issue: 9(3), pp. 957-964, 2018.

[16] S. Z. A. S. K. Bahrin and S. Jaafar, "Nitial Development of anElectrical Power Generator by using Thermoelectric Generator, Focal Lens and Underground Heat Dissipation System," International Journal of Electrical and Computer Engineering, vol/issue: 8(4), pp. 2549-2556, 2018.

[17] A. A. Angeline, et al., "Performance Analysis of $\left(\mathrm{Bi}_{2} \mathrm{Te}_{3}-\mathrm{PbTe}\right)$ Hybrid Thermoelectric Generator," International Journal of Power Electronics and Drive System, vol/issue: 8(2), pp. 917-925, 2017.

[18] A. Angeline and Jayakumar, "Performance Analysis of $\left(\mathrm{Bi}_{2} \mathrm{Te}_{3}-\mathrm{PbTe}\right)$ Hybrid Thermoelectric Generator," International Journal of Advances in Applied Sciences, vol/issue: 5(1), pp. 32-44, 2016.

[19] Zhou M., et al., "A heat transfer numerical model for thermoelectric generator with cylindrical shell and straight fins under steady-state conditions," Applied Thermal Engineering, vol. 68, pp. 80-91, 2014.

[20] Chandy R. M., et al., "Design and analysis of heat exchanger for automotive exhaust based thermoelectric generator," International Journal for Innovative Research in Science \& Technology, vol/issue: 1(11), pp. 291-298, 2015.

[21] H. K. Ma, et al., "Waste heat recovery using a thermoelectric power generation system in a biomass gasifier," Applied Thermal Engineering, vol. 88, pp. 274-279, 2015.

[22] Barma M. C., et al., "Estimation of thermoelectric power generation by recovering waste heat from Biomass fired thermal oil heater," Energy Conversion and Management, vol. 98, pp. 303-313, 2015.

[23] Baskar P., et al., "Experimental Analysis of Thermoelectric Waste Heat Recovery System Retrofitted to Two Stroke Petrol Engine," International Journal of Advanced Mechanical Engineering, vol. 4, pp. 9-14, 2014.

[24] Wang Y., et al., "Theoretical analysis of a thermoelectric generator using exhaust gas of vehicles as heat source," Applied Energy, vol. 112, pp. 1171-1180, 2013.

[25] Hsiao Y. Y., et al., "A mathematic model of thermoelectric module with applications on waste heat recovery from automobile engine," Energy, vol/issue: 35(3), pp. 1447-1454, 2010.

[26] D. Champier, et al., "Thermoelectric power generation from biomass cook stoves," Energy, vol/issue: 35(2), pp. 935-942, 2010.

[27] Niu X., et al., "Experimental study on low-temperature waste heat thermoelectric generator," Journal of Power Sources, vol/issue: 188(2), pp. 621-626, 2009.

[28] Maneewan S. and Chindaruksa S., "Thermoelectric Power Generation System Using Waste Heat from Biomass Drying," Electronic Materials, vol/issue: 38(7), pp. 974-980, 2009.

[29] Nuwayhid R. Y., et al., "Development and testing of a domestic woodstove thermoelectric generator with natural convection cooling," Energy Conversion and Management, vol. 46, pp. 1631-1643, 2005.

[30] Gou X., et al., "Modeling, experimental study and optimization on low temperature waste heat thermoelectric generator system," Applied Energy, vol/issue: 87(10), pp. 3131-3136, 2010.

[31] "Specification of TE Modules," Available from: https://hong-lang.en.alibaba.com. Accessed 4 April 2017.

[32] "Specification of TE Modules," Available from: http://www.ebay.com. Accessed 16 March 2017. 